\title{
Device for automation of hydrostatic leveling of man-made structures with alternative power supply
}

\author{
Nematjon Zaxidov ${ }^{1}$, Shoakbar Shoyusupov ${ }^{2}$, Shahzod Rahmatillayev ${ }^{1}$, Tulqin Jamolov ${ }^{1}$, \\ and Doniyor Gafurov \\ ${ }^{1}$ Named after I. Karimov Tashkent State Technical University, Tashkent, Uzbekistan \\ ${ }^{2}$ Tashkent institute of irrigation and agricultural mechanization engineers, Tashkent, Uzbekistan
}

\begin{abstract}
The article discusses the issue of ensuring the reliability, durability, and safety of buildings and engineering, including hydraulic structures, by creating an automated hydrostatic leveling system with a device that uses fiber optics combined with an LED and a photodetector, installed on one hollow axis of rotation of the drum, like a sensor a ferromagnetic transducer was used for the displacement pulse, a comparative analysis of the existing means for measuring settlements and deformations of objects using laser and photoelectric means was carried out. A patented device has been developed that provides high accuracy, reliability, and the ability to create a monitoring system with remote information delivery with an autonomous energy source. The device can be used to install and assembly conveyor lines in determining the vertical deformations of dams, buildings, and structures during operation.
\end{abstract}

\section{Introduction}

With an increase in the requirements for reliability, durability, safety, environmental friendliness of buildings, engineering, including hydraulic structures, the importance of monitoring their operation, the movements of bases and deformations of structures occurring over time, predicting their states during operation, for timely taking the necessary measures to strengthen them, including technogenic processes, are carried out through regular field observations, the technique and methodology of which requires constant improvement. This is especially true for seismically active regions, where the time factor (efficiency) often turns out to be decisive, and high information content of field observations is required.

The practice of production of engineering and geodetic surveys. measurements when observing settlements and deformations of engineering structures are mainly based on the use of visual-optical devices, which, by their design and principle of operation, often do not provide the necessary efficiency, \}information content and productivity measurement process [1-4], [23].

The main direction of improving the technology of engineering and geodetic measurements is introducing methods and tools based on the use of laser, LED, infrared, and other radiation sources in conjunction with photoelectric and optoelectronic recording 
devices. [5]. For the automation of geodetic measurements, ray and interference lines were used as reference (reference) lines in alignment measurements. The following methods of alignment measurements have already become classical.

According to Young's scheme, the diffraction method provides high measurement accuracy of the order of 30-40 microns. However, the need for the performer's participation limits the automation process; another disadvantage of the method is the small range of the alignment (up to $80-100 \mathrm{~m}$ ).

The dispersion method based on the Fraunhofer diffraction theory provides a mediumrange and high accuracy; the disadvantage is the complexity of the automation process. The interference method has a large, about $1000 \mathrm{~m}$ range, high accuracy, but high requirements for the accuracy of manufacturing and use of zone plates; the influence of chromatic and spherical aberration limits its application. [6]

In the practice of automation of measurements of settlements and deformations, hydrostatic measuring systems with remote information counting have been used. [7]

Recently, the method of hydrostatic leveling has been received mainly at hydraulic structures due to its advantages:

-the application does not require high qualifications of the performer;

-the possibility of the automation method;

- high accuracy and efficiency of measurements than with geometric leveling;

- determination of draft points, etc. in hard-to-reach places;

- less time wasted than with geometric leveling.

The simplest measurement methods include visual registration methods, such as an MK-25-70 or MK-25-50 micrometer with a registration accuracy of $0.01 \mathrm{~mm}$. This method is low-performance and laborious, excludes the possibility of automation, and the presence of subjective errors of the observer limits the accuracy of measurements.

The operation of the hydrostatic system of the design of the NIS Gidroproekt IVD, made with the possibility of remote information retrieval, is based on measuring the vibration frequency of a stretched string with a load immersed in a liquid.

Three options have been developed; IVD-30 - range - $30 \mathrm{~mm}$, IVD-100 -100 mm, and IVD-300 range $300 \mathrm{~mm}$, providing an accuracy of $0.15 \mathrm{~mm}$. The disadvantage is low measurement accuracy.

In [8], hydrostatic levels with electrocontact and photoelectric recording methods, including a capillary recorder, are considered.

One of the simplest registration methods is the electrocontact method (Figure 1)

Filling hydrostatic meters with salt water (to increase the electrical conductivity) leads over time to corrosion, which touches the part of the stylus cone, which also reduces the accuracy.

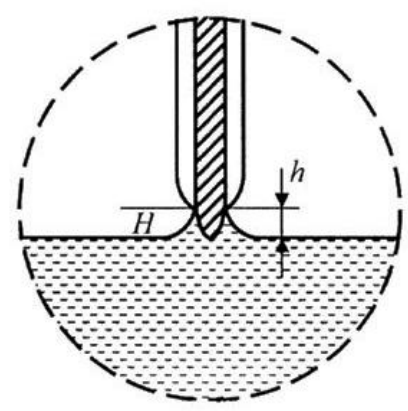

Fig. 1. Hydrostatic level with insulating cone 
According to the principle of registration, hydrostatic levels can be represented as a block diagram shown in Fig. 2

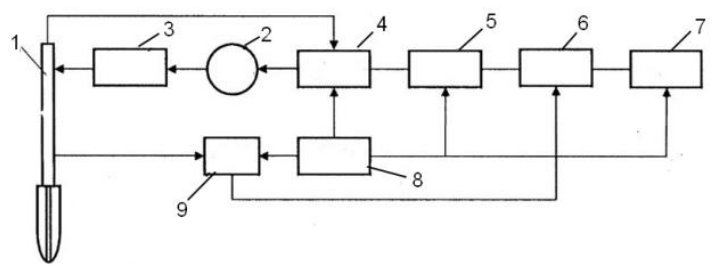

Fig. 2. Functional block diagram of hydrostatic levels with electric contact registration: 1 is probe, 2 is electric motor, 3 is drive unit (rack or cam mechanism), 4 is electric motor control unit, 5 is control panel, 6 is counter, 7 is indicator, 8 is power supply, 9 is photo sensor.

\section{Results and Discussion}

Based on hydrostatic sensors of electrocontact and photoelectric types, for high-precision remote measurements of the excess of control points, the hydrostatic leveling systems SGN-27D, SGN-54D, as well as the SGN-VI system (for hydroelectric power plants of thermal power plants, elevators, etc.) can be used. [9]

The disadvantages of the considered hydrostatic sensors are decreased accuracy of measurements over time for electrocontact types and the complexity of the mechanical and electronic parts of both electrocontact and photoelectric sensors for converters of rotation into a pulse or code.

It is necessary to develop a hydrostatic level in which a photo converter of linear (rotating) displacements into a pulse or code is excluded, to increase the measurement range, to exclude electrical contact or light recording of the liquid level, in which there are no optical or electrical characteristics of the measured level of the liquid surface.

Table 1. Main technical characteristics of the SGN-54D system

\begin{tabular}{|c|c|c|}
\hline Measuring range & Power consumption & Measurement accuracy, $\tau$ \\
\hline 1.Up to $10 \mathrm{~mm}$ & 100 & 20 microns \\
2. Up to $50 \mathrm{~mm}$ & $-"-$ & 50 microns \\
3. Up to $100 \mathrm{~mm}$ & $-"-$ & 100 microns \\
\hline
\end{tabular}

There is a method of resistive level determination (liquid or solid) (see AS No. 847054, G01F23 / 44), [10] in which this method is used, which is distinguished by its simple design.

The disadvantages of the known device are:

- limited measuring range due to limitation of the cable length;

- insufficient reliability and accuracy of measurements due to the influence of the temperature coefficient of resistance and in the homogeneity of the high-resistance conductor;

- functionality, because the device is designed to measure the level of liquid media;

- limited measurement accuracy.

To solve this problem, a level gauge sensor for use in hydrostatic leveling (AS No. 1789873) and a photoelectric remote level gauge have been developed [11]. 


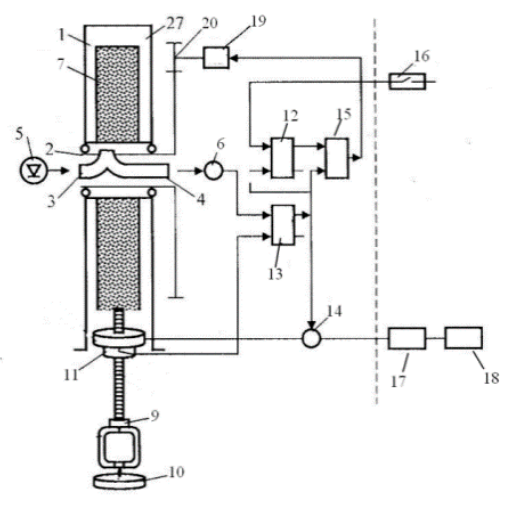

Fig. 3. Electronic block - circuit and mechanical part of the level gauge.

Figure 3 shows the electronic block diagram and the mechanical part of the device (for clarity, the thickness of the fiber-optic cable is shown thickened); Fig. 4 - placement of a fiber-optic bundle in the hollow axis of the drum; Fig. 5 shows an enlarged view of the mutual arrangement of the shutter between the ends of the fiber-optic bundles.

The main distinguishing features of the proposed device are the use of fiber optics [1214], a float, and a magnetic displacement transducer.

The level gauge consists of a drum 1 , made with a through axial hole 2 , in which two fiber-optic bundles 3, 4 are laid, each end of the drum faces two opposite openings of the axial channel, where LED 5 and photodetector 6 are coaxially mounted, and the second ends of the bundles come out through the hole of the axial channel and are combined into one bundle-cable 7, on which there are marks made of ferromagnetic material and covered with an elastic protective film the bundle-cable 7 is laid on the drum 1 and passed through the inductive pulse sensor 8 ,

with a ring magnet 9, a shutter with an opening in the lower part, made with the possibility of moving in the vertical direction, connected with the float 10 and the stop 11 , the end ends of the bundles 3, 4 are turned towards each other, two RS triggers 12, 13, an electronic key 14, trigger 15, magnetically controlled switch 16, counter 17 and indicator 18 , connected through a communication line, a brushless motor control unit 19, connected to the drum 1 through a kinematic connection 20 .

The described device works as follows.

In the initial state, the luminous flux from the LED 5, entering through the end end of the fiber-optic bundle 3 , is shaded by an opaque section of the shutter, because the float 10 associated with it is in the lower position relative to the housing, the optical assembly itself is in the extreme upper position, the upper outputs of the triggers 12,13 are closed, the motor 20 is de-energized, when the command "start" is given by means of a magnetically controlled switch, trigger 12 is opened, the control unit, the electric motor 19 turns on and begins to rotate the drum 1 through the kinematic transmission 20, the cable 7 with the float 10 and the optical unit will begin to descend, the impulses of the sensor 8 appearing at the intersection of each ferromagnetic mark will not go to the counter 17 , moving towards the drum, the magnet 9 of the optical unit reaches the trigger 15, which will turn off through the trigger 13, the control unit and the electric motor, 19 on the indicator 18, the number of pulses is recorded in proportion to the distance to the liquid level. As soon as the float 10 reaches the surface of a liquid or a granular medium and slows down, as a result of the movement of the housing, the luminous flux from the end exit of the fiber-optic bundle 3 through the shutter hole enters through the end of the second bundle 4 to the photodetector 6 . As a result, the trigger 13 opens, in which the second trigger input 12 will receive a pulse and close it, the control unit 24 will change the polarity of the voltage. The electric motor 
19 and the drum 1 will start to rotate in the opposite direction, at which the cable 7 will start to wind onto the drum, the electronic key will open at the same time, the pulses from the sensor 8 will begin to flow to the counter 17, moving towards the drum, the magnet 9 is optical the node reaches the switch 15 , which turns off the trigger 13, the control unit and the electric motor 19 on the indicator 18 , the number of pulses is recorded in proportion to the distance to the liquid level. Thus, in the proposed device, it is possible to increase the measurement range by laying the cable layer by layer directly behind each other and in a row to the drum walls in comparison with the prototype. In contrast, the cable length is not limited. In contrast to the analogue, the proposed device operates on the principle of sequential information transmission, which is more convenient to transmit at a distance than an analog signal and convert it into a digital code.

It should be noted that the device, after starting, works in automatic mode; it can be controlled and transmitted the received information from a distance.

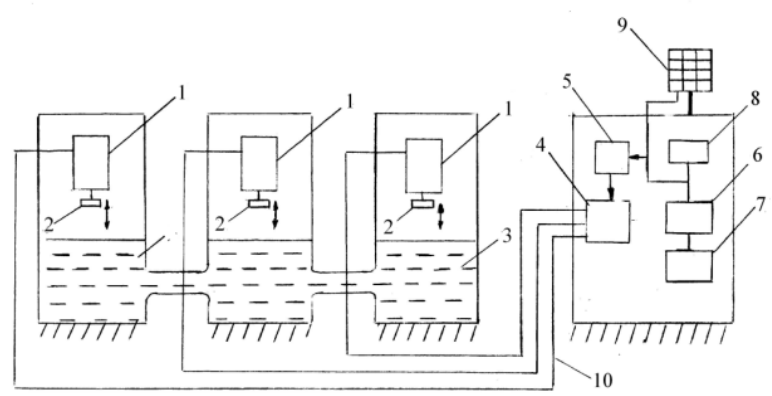

Fig. 4. Harness laying form

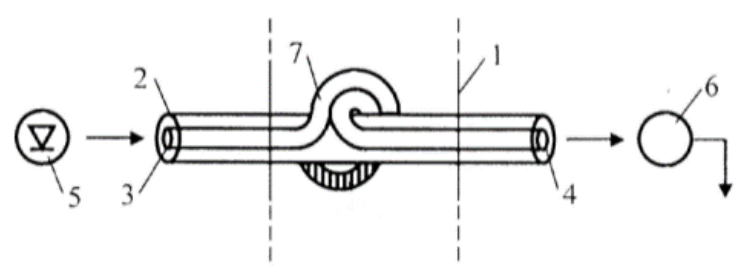

Fig. 5. Installing the float

The main factor in assessing the measurement accuracy is resolving the readout of the signals by the head from the ferromagnetic tape. At a tape speed $\mathrm{Vm}=3 \mathrm{~cm} / \mathrm{s}$, the maximum reproduction frequency is of the order of $v \mathrm{~m}=3000 \mathrm{~Hz}$, it takes $1 / 30 \mathrm{~s}$ to move the tape by a distance of $1 \mathrm{~mm}$, therefore, the number of pulses $\mathrm{n}=1 / 30 \mathrm{v}=1 / 100$ is converted, which will be an accuracy of $0,01 \mathrm{~mm}$, i.e., the higher the recording frequency $v m$, the higher the accuracy.

Another important factor influencing the measurement accuracy is the coefficient of thermal expansion of a fiber-optic bundle made of glass (crown glass, fling glass).

The thermal expansion coefficient of glass according to $[15,16]$ is $\alpha \mathrm{c}=8.5 \cdot 10-6 \mathrm{k}-1$, or from $0^{\circ} \mathrm{C}$ to $40^{\circ} \mathrm{C}$, glass expands $\alpha$ from 0 with the condition to $-0.5 \cdot-6 \mathrm{k}-1$, i.e., e. glass has a very low coefficient of thermal expansion, for example, platinum has a coefficient of thermal expansion $\alpha \mathrm{n}=8.9 \times 10-6 \mathrm{k}-1$, and pyrex glass is $3 \times 10-6 \mathrm{k}-1$. With a fiber optic bundle length of $1,000 \mathrm{~mm}$, its length will increase by only $0.01 \mathrm{~mm}$. 


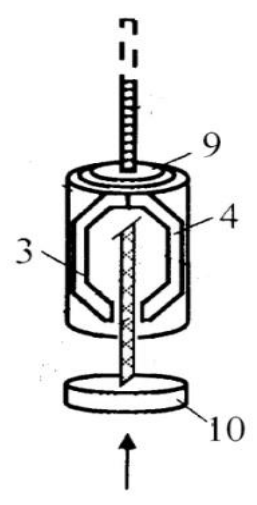

Fig. 6. Hydrostatic leveling scheme with an autonomous power source.

Considering that the developed level gauge is designed for a low-voltage power supply (9$12 \mathrm{~V}$ ) to increase the frequency of the measurement process and increase efficiency, it is proposed to use a solar photovoltaic battery as an alternative power source [17-22]. Figure 6 connected through controller 2 and voltage stabilizer 3 to storage battery 4 , from it to electrical circuit 5 and switching unit 6 providing a sequence of switching on through cable communication line 7 , level gauges 8 with floats 9 installed at points of interest in housings interconnected by hoses and containers ... with liquids 10 .

Using the switching unit 6 , a specific point is selected, and the measurement process is carried out in automatic mode. In contrast, the offset value after the measurement cycle is transmitted through cable 7 to the indicators. Due to the use of a light-guide bundle with a float instead of the electrocontact method, the required measurement accuracy is ensured by eliminating the need to monitor the corrosion of the contact probe.

The proposed level gauge can be used for the installation and assembly of technological equipment, studies of vertical deformations of dams, buildings, and other hydraulic facilities during operation, and can also be used to determine the water level in hydrosystems in a wide range of measurements of the level height with high accuracy.

\section{Conclusion}

The study was supported by Tashkent State Technical University and Tashkent institute of irrigation and agricultural mechanization engineers.

\section{References}

1. Automation of geodetic measurements in land reclamation construction. NeumyvakinYu.K., Persky MI, and others - M. Nedra p. 38; (1984).

2. Guidance on field observations of deformations of hydraulic structures and their foundations by geodetic methods. M. Nedra p. 194; (1980).

3. Geodetic support for the construction, installation and operation of engineering structures. Interved.Collection of scientific papers. M. TsNIIGAIK, p. 114; (1988)

4. Karlson AA, Guide to field observations of deformations of hydraulic structures and their foundations by geodetic methods. M. Energy (1980).

5. Kamen H., Electronic measuring methods in geodesy, Translated from German, M. Nedra pp. 25-41; (1982). 
6. YanbaevKh.K., Special devices for engineering - geodetic works, M. Nedra, pp. 69115; (1990).

7. Geodetic methods for studying the deformation of structures. - M. Nedra, p. 186; (1991).

8. Zatsariyny AV, Automation of high-precision engineering and geodetic measurements, M. Nedra, p. 156; (1976).

9. Reference book of a surveyor 2. p / r Bolshakov VD, Levchuk GG, M. Nedra, pp. 362-386; (1985).

10. SU No. 847054 Level gauge G01F23 / 44 (1978).

11. SU No. 1789873. Photoelectric remote level gauge auth.Zakhidov N.M., MurzaikinI.Ya. publ. 01/23/1993 G01F23 / 32.

12. US patent No. 4291224. Fiber-optical position sensor with digital indication MKIG01D5 / 34, NKI 356-150.

13. Japanese patent No. 59-40273, Light guide for an optical rangefinder publ. 09/28/1984 G01B7 / 48, G02B5 / 14.

14. Zakhidov N.M, Samborskiy A.A, Saitov E.B., Rakhmatillaev Sh.F ..Electronic recorder of deviation from straightness with an optical-fiber analyzer of photoenergy given nanostructures. International conference on pp. 179-183; October 9-10, (2020).

15. Koshkin N.M, Shirkevich M.G. Handbook of elementary physics - M. Science p. 207.

16. Applied optics n / a ordered n.p. M. Mechanical Engineering, pp. 128-132; (1988).

17. Zikrillaev, Saitov E.B., Zhuraev. Optimization of calculation of complex renewable energy systems for use at autonomous facilities [Integration of science, education and innovation from the development of modern microelectronics] Andijan - (2020) Resp.ilm - practical conference;

18. Zakhidov N.M., Saitov E.B., Botirov B.M. and others. Theoretical prerequisites for optimization of an autonomous combined system;

19. U.Sapaev, E. Saitov, N. Zaxidovand B. Kamalov [Matlab -model of a solar photovoltaic station integrated with a Local electrical network] IOP ConferensSceries: Material Science and Engineering 883 012116; (2020).

20. N. Zaxidov, Raxmatillaev Sh., Gafurov D., Electronic recorder of deviation from straightness with optical-light guide analyzer https://doi.org/10.1051/e3scomf/20202116901148 E3S Web of conference 21601148 (2020).

21. Sh. Shoyusupov, Sh. Rakhmatullaev, Sh. Shoyusupov "Investigation of the transient characteristics of s-diodes based on silicon compensated by vanadium" $1^{\text {st }}$ International Conference on Enerdetics, Civil and Agricultural Engineering 2020, Tashkent, Uzbekistan October $14^{\text {th }}-16^{\text {th }}(2020)$.

22. Denmuhammadiev A.M., ShoyusupovSh.A.,ChullievYa.E. Low-power solar stations on dam surfaces of reserrvoirs. International Scientific and Technical Conference "Construction Mechanics, Hydraulics and Waer Resources Engineering" Topic: Mechanization, electrication of agriculture and renewable energy, Tashkent, Uzbekistan.-23-25aprel.

23. Baratov R., Berdishev A. Autonomous Water Disinfection Complex for the Rural Location Journal of Scientific and Engineering Research, Volume 5, Issue 8,. - pp. 22 $-29,(2018)$. 